JOURNAL OF CASE REPORTS $2014 ; 4(2): 300-303$

\title{
Villous Adenoma Arising Within Intestinal Metaplasia on the Bladier Dome
}

Christos Papandreou', Nikolaos Manolakis' ${ }^{1}$ Antigoni Skopelitou ${ }^{2}$

From the Department of Urology' and Department of Pathology ${ }^{2}$,

General Hospital of Arta, Greece.

Abstract:

Villous adenoma (VA) of the urinary bladder is rare tumor. Intestinal metaplasia (IM) is the less common type of cystitis glandularis. We report a case of a 78 year-old lady who was diagnosed with VA on the set of IM on the bladder dome. There was no sign of recurrence 12 months following transurethral resection.

Key words: Adenoma, Villous, Cystitis, Metaplasia, Urinary Bladder Neoplasms.

\section{Introduction}

Villous adenoma (VA) is uncommon premalignant neoplasm of the gastrointestinal tract [1]. Its occurrence in the urinary tract is rare. A few case reports and case series of VA with less than 70 patients have been reported in the English literature [2]. It is associated with cystitis glandularis (CG), which is a relatively common proliferative disorder of the urinary bladder mucous glands [3]. Two subtypes of CG exist: typical/usual type and the less common intestinal type, also known as intestinal metaplasia (IM) [4]. . We report coexistence of VA and $I M$ in a 78 year-old lady.

\section{Case Report}

A 78 year-old lady presented to the urology department for the investigation of urinary bladder mass which was incidentally identified by ultrasound abdomen. Cystoscopy revealed an exophytic round lesion with mucin secretion on the dome measuring
$2 \times 2 \mathrm{~cm}$. [Fig. 1a,b]. A transurethral resection was performed.

Pathologic examination with routine Haematoxylin and Eosin stain showed intestinal metaplasia (IM) with presence of goblet and scattered Paneth cells, on the set of which a villous adenoma (VA) without any significant degree of cytologic atypia and only focally mild epithelial dysplasia, was noticed [Fig.2a,b]. Histochemical assay for periodic acidSchiff (PAS) stain and Alcian-Blue mucin detection was positive [Fig.3a,b]. Immunohistological examination showed strong immunoreactivity for Cytokeratin 20 [(Fig.4] and negativity for cytokeratin 7, whereas typical cystitis glandularis is characterized by the opposite cytokeratin immunoprofile.

Cystoscopy and CT abdomen/pelvis at the first 3-month follow-up did not reveal any sign of recurrence. Cystoscopy at 12 months following

Corresponding Author: Dr. Christos Papandreou

Email: cpapas@otenet.gr

Received: June 27, 2014 | Accepted: July 22, 2014 | Published Online: August 15, 2014

This is an Open Access article distributed under the terms of the Creative Commons Attribution License (creativecommons.org/licenses/by/3.0)

Conflict of interest: None declared | Source of funding: Nil | DOl: http://dx.doi.org/10.17659/01.2014.0075 
resection was also negative.

\section{Discussion}

Villous adenoma (VA) of the urinary bladder is histologically similar or identical to its counterpart in large intestine [4]. It usually presents with haematuria and/or difficulty in micturition and rarely mucinuria. The majority of cases occur on the urachus, bladder dome and trigone. It is associated with cystitis glandularis (CG) and the prognosis is excellent when it is resected completely. Differential diagnosis must include adenocarcinoma, with which it may also coexist $[2,3,5,6]$. Although there is no evidence of progression of VA to adenocarcinoma in the bladder, this has been reported in a female urethra [7].

Intestinal metaplasia (IM) is histologically differentiated from the usual type of CG by the presence of mucin-producing goblet cells and sometimes Paneth cells [4]. CG occurs usually on the bladder trigone and is generally asymptomatic. In contrast to VA it is rarely accompanied by macroscopic findings. If this happens, it may cause bladder outlet or upper tract obstruction $[8,9]$.

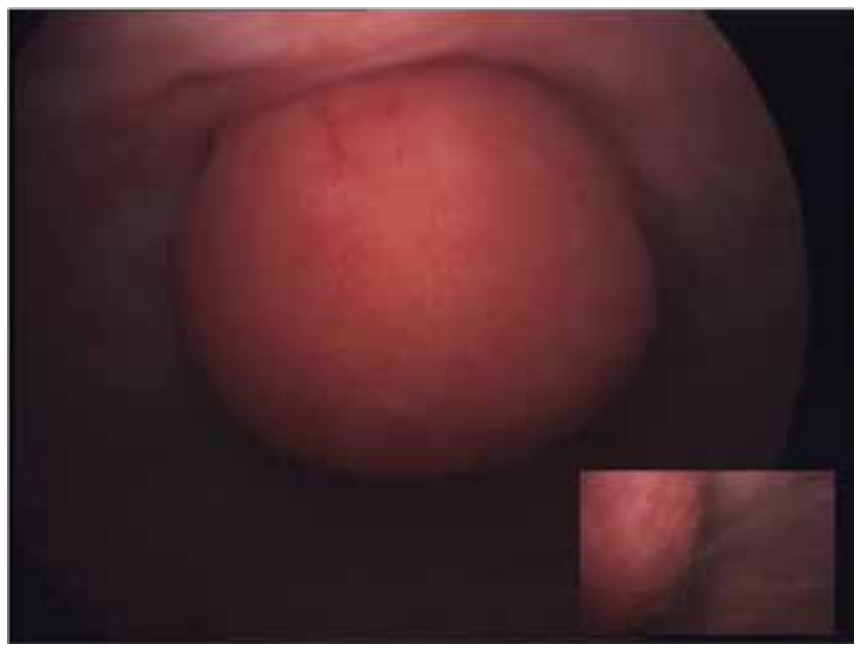

Fig.1: Cystoscopy showing villous adenoma on the dome, b) Inset: mucin secreted by the tumor.
Although the usual type of $C G$ is considered a benign epithelium metaplasia, IM has been suggested to be a precursor in the development of adenocarcinoma $[10,11]$. However, other findings did not support IM's preneoplastic role [12].

Our case is clinically interesting not only because of its rarity, but also because it provides additional evidence on the close relation between VA and IM. Our case demonstrates clearly that VA may arise inside IM and that this may occur on the bladder dome. Moreover, the case is clinically important due to the association of these two entities with bladder malignancies, particularly adenocarcinoma.

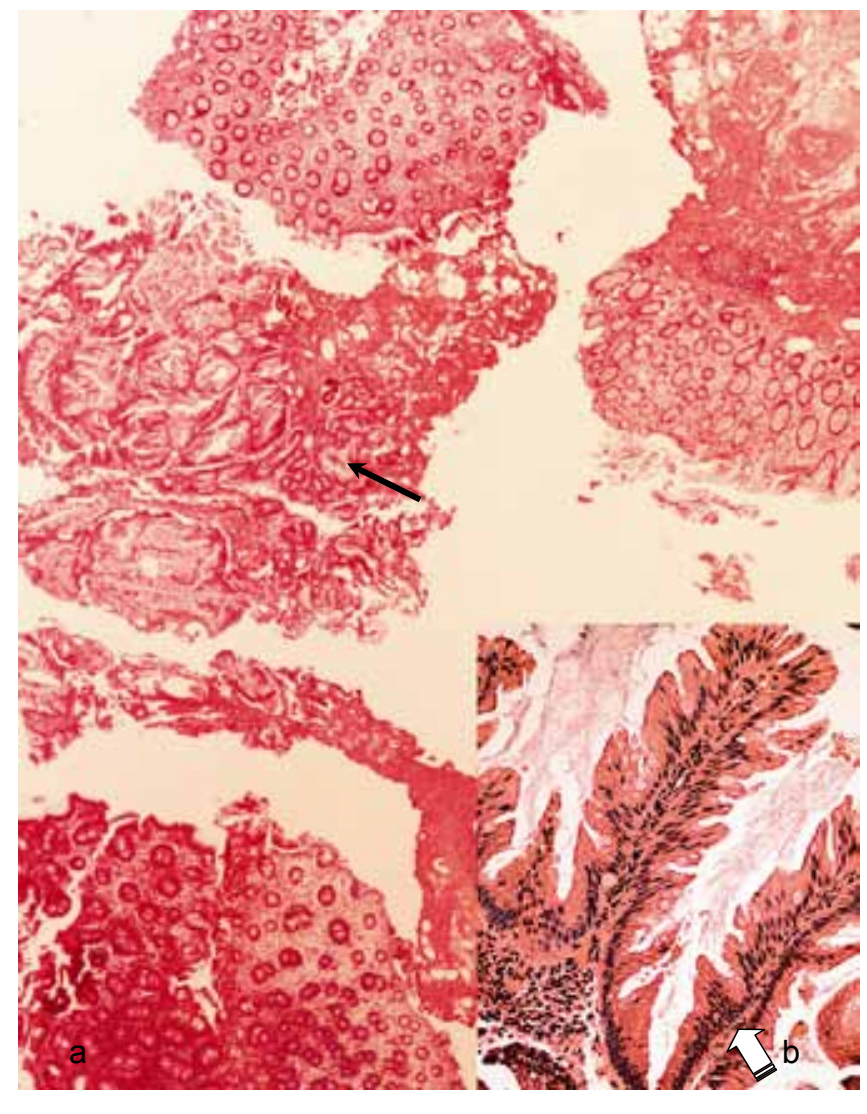

Fig.2:(a) Intestinal metaplasia ( $H$ \& E x 40). Notice the villous polypoid proliferation (black arrow) (b) Inset: greater magnification of the lesion (H \& E x 200), shows villous adenoma with focal mild dysplasia (white arrow). 


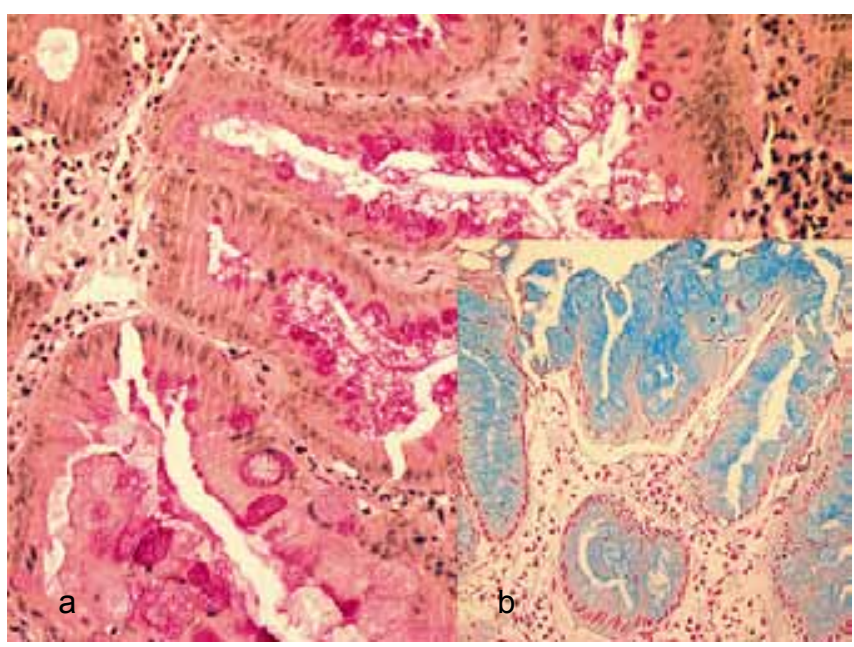

Fig.3: (a) PAS histochemical stain depicting intracytoplasmic mucin in intestinal epithelium within goblet cells (x 400); (b) Inset: Alcian - Blue histochemical staining in the same area (x 200).

Complete transurethral resection of VA is the standard treatment and provides excellent prognosis. In our case there was no evidence of tumor recurrence 12 months after resection.

\section{Conclusion}

VA of the urinary bladder is rare tumor associated with IM. Both entities can coexist on several bladder sites including the dome. Due to their association with adenocarcinoma, annual follow-up cystoscopy is recommended.

\section{References}

1. Toughrai I, Mellouki I, Kamaoui I, Ait Laalim S, Ibn Majdoub K, Mazaz K, et al. Surgical Management of Large Villous Tumours. Journal of Case Reports. 2013;3:24-29.

2. Kato Y, Konari S, Obara W, Sugai T, Fujioka T. Concurrence of villous adenoma and non-muscle invasive bladder cancer arising in the bladder: a case report and review of the literature. BMC Urol. 2013;13:36.

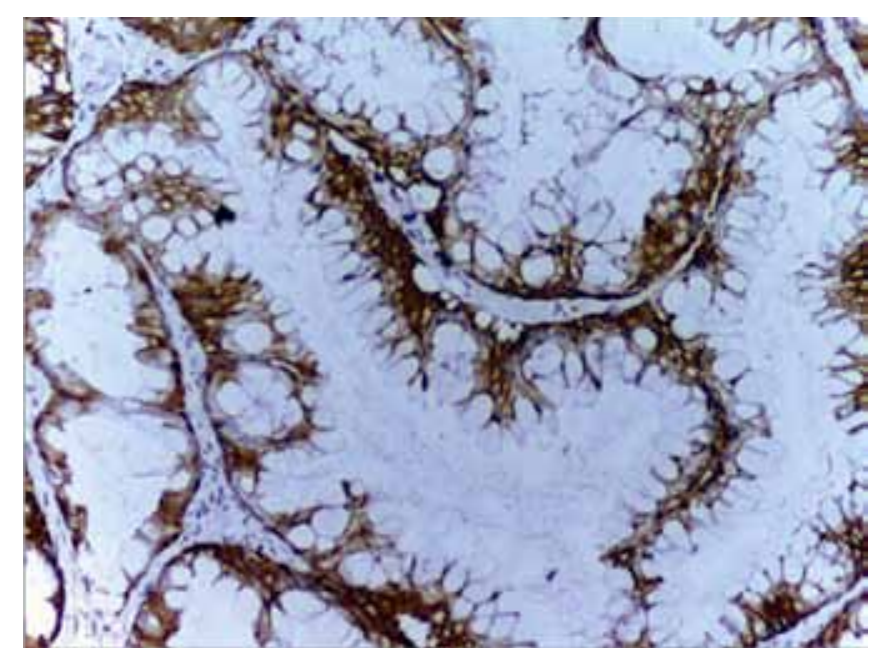

Fig.4: Strong immunohistochemical cytokeratin (CK) 20 expression in intestinal metaplasia/ villous adenoma region (x 400).

3. Sung W, Park BD, Lee S, Chang SG. Villous adenoma of the urinary bladder. Int J Urol. 2008; 15(6):551-553.

4. Williamson SR, Lopez-Beltran A, Montironi $R$, Cheng L. Glandular lesions of the urinary bladder: clinical significance and differential diagnosis. Histopathology 2011;58(6):811834.

5. Cheng L, Montironi R, Bostwick DG. Villous adenoma of the urinary tract: a reportof 23 cases, including 8 with coexistent adenocarcinoma. Am J Surg Pathol. 1999;23(7):764-771.

6. Seibel JL, Prasad S, Weiss RE, Bancila E, Epstein Jl. Villous adenoma of the urinary tract: a lesion frequently associated with malignancy. Hum Pathol 2002;33(2):236-241.

7. Powell I, Cartwright H, Jano F. Villous adenoma and adenocarcinoma of female urethra. Urology $1981 ; 18(6): 612-614$.

8. Michajłowski J, Matuszewski M, Kłącz J, Gibas A, Biernat W, Krajka K. Acute urinary retention in a patient with extended cystitis glandularis. Cent European J Urol 2011 ;64(2):94-96.

9. Li A, Liu S, LuH, Zhang F, Lu J, Wang H, etal. Clinical character of cystitis glandularis accompanied 
with upper urinary tract obstruction. Can Urol Assoc J 2013;7(11-12):E7 08-10.

10. Morton MJ,Zhang S, Lopez-Beltran A, MacLennan GT, Eble JN, Montironi R, et al. Telomere shortening and chromosomal abnormalities in intestinal metaplasia of the urinary bladder. Clin Cancer Res 2007; 13(20):6232-6236.

11. Thrasher GB, Rajan RR, Perez LM, Anderson
EE. Cystitis glandularis. Transition to adenocarcinoma of the urinary bladder. N. C. Med J 1994;55: 562-564.

12. Smith AK, Hansel DE, Jones JS. Role of cystitis cystica et glandularis and intestinal metaplasia in development of bladder carcinoma. Urology. 2008;71(5):915-918. 